\title{
Promoting English Vocabulary for Autistic Students by Using Speech Therapy (An Action Research in Sunan Muria Extraordinary School, Kudus)
}

\author{
Farid Noor Romadlon ${ }^{1}$ \\ ${ }^{1}$ Universitas Muria Kudus, Central Java, Indonesia \\ ${ }^{1}$ farid.noor@umk.ac.id \\ Gudnanto $^{2}$ \\ ${ }^{2}$ Universitas Muria Kudus, Central Java, Indonesia \\ 2 gudnanto@umk.ac.id
}

\begin{abstract}
The opportunity to learn English should be given to all learners since English has been widely spread globally. Learners should be exposed to English as early as possible and be prevalent for all, including disabled students. Students who need special treatment in learning should also get equal opportunity to study, especially English. One type of disabled students who need special attention in English learning is those who have autism. Autistic students are in need of special treatment learning English since they have more difficulties in perceiving and producing language code. Therefore, English teachers should have awareness of the characteristics of autistic students concerning speech difficulties. It is highly necessary for autistic students to have intensive therapy and in other sides, they also have a right to learn foreign languages like English. Speech therapy as one of the therapies used to assist the autistic students in producing language codes is potentially in line with English learning. In this case, speech therapy can be done while teaching English to autistic students because speech therapy often requires graded language teaching. This study focuses on how speech therapy is integrated with English teaching for autistic students in Second Grader of Junior High School students to improve their English proficiency and speech competence as well. The study is an ongoing classroom action research conducted in SMP Sunan Muria in Kudus Regence, Central Java, Indonesia.
\end{abstract}

ARTICLE HISTORY

Received 27 April 2017

Accepted 19 September 2017

\section{KEYWORDS}

Speech therapy; English

learning; Autistic students

\section{Introduction}

Observing the faster development of technology and communications requires a versatile instant motion because it has the effect of influencing the human lifestyle that is easy, practical, and economic and so on. Sometimes people forget that not all are practical and economical it is good for human health and without realizing the development of the disease are also more and more. One of the effects dealing with 
the lifestyle is coming to the next-gen, children. Autism is one of the effects in which a condition that causes the child has a behavior is not concerned with the social environment that can affect language development or delayed speech. Where previously stated that children with autism could not be cured. However, there is a possibility of healing and quicker for autism if known earlier by both the doctor and his family will be handled more quickly. Even abroad, there have been people with autism have been able holds a doctorate. Within the last 10 years has been a lot of institutions that deal with autism, through the appropriate treatment in the form of medicine, food, talk therapy with PECS (Pictures Exchange Communication System), and talk therapy with Lovaas method is often called the ABA (Applied Behaviour Analysis) is desperately needed by children with autism.

Parents and doctors should know the symptoms is that the symptoms of autism begin to appear before three years old which covers the areas of interaction, communication and behavior and how to play which is not like other children. The type and weight of the symptoms of autism vary between each child. Infatil classic autism showed all the symptoms in severe degree, but the group PDD-NOS (Pervasive Developmental Disorder-Not Otherwise Specified) only shows part of the symptoms. Another difficulty is that some of these symptoms can occur in normal children, just the intensity and quality is different. Disturbances in communication become the main factor of the obstacles to interact with their social environment. So, communication becomes essential therapy for the healing of children with autism. Communications to build concentrations in children with autism will become a significant therapy with a cure rate. Lovaas method combined with Picture Exchange Communication Strategy is a method that emphasizes behavioral analysis and communication improvement are expected to support the children improvement in communication, especially foreign language. Children with autism experience a complex developmental disorder that they are also called impaired pervasive. Peeters (2004: 4) defines pervasive that suffered damages far in covering the whole of the child. The term also based pervasive developmental disorder exhibited by children with autism. Disturbances that almost cover all aspects of life, such as communication, social interaction, impaired in sensory patterns of play, typical behaviors, and emotions (Peeters, 2004: 5). Such defects will block the development of children with autism. Some obstacles or disturbances that are often exhibited by children with autism, such as Language development is slow or completely nonexistent, the child looks like deafness, difficult to speak, or ever been talking but then disappear, sometimes the words used are not meaningful, meaningless babbling in repetitive language that cannot be understood by others, talk is not used for a tool to communicate, glad to mimic or imitate (echolalia), when pleased mimic, can be memorized exactly the words or singing but do not understand it, most of the children with autism do not speak (non-verbal) or a little talk until adulthood, happy tugged at the hands of others to do what he wants. 


\section{Basic Concept Communications}

Communication is often defined as the ability to speak, but wider than the communication of language and speech. Therefore, it is necessary explained in the definition of communication. Sunardi et al. (2006) define Communication as means delivery of a statement by a person to other/s as a consequence of social relationships. It emphasizes communication as a tool of social relationships. To perform its role as a social human being have to communicate. Another opinion from Quill (1995) in Gardner, et al. (1999: 2) states that the communication is a dynamic process in which a process of messenger encoding and decoding of the message recipient, information exchange occurs, the delivery of the feelings (emotions), there are specific goals and no submission of ideas. It can be taken into account that communication always involves two or more individuals and most importantly the desire, intent, or purpose message sender of the message can be received and understood by the recipient of the message. Communication is an important aspect to express feelings, ideas, desires, and needs.

To make communication turns out necessary tools and the main tool in communication is language (Jordan et al., 2002). Means of communication involves verbal and non-verbal language, including oral, written, sign language, body language, and facial expressions.

From the above understanding of communication, there are three important things related to communication. First, the communication must involve two or more people. Second, communication is an exchange of two-ways information, and the third involves understanding. Moore (1987) strengthens the previous ideas about communication that it is effective only if an idea can move from the notion of someone to thoughts of others.

Also, communication is a dynamic process that uses language as a primary tool in the context of individual social relationships with other individuals who are in it involves the expression of feelings, submission of ideas, desires, needs, and goals.

\section{Communication Development in Children}

Communication development of children, in general, originated from a crying baby who told his mother that he was hungry or uncomfortable. About two months of age babies are noises (cooing) or laugh when s/he was happy. Then, it develops into babbling or the repetition of consonant-vowel sequence, for example, ma-ma-ma, baba-ba. The age of about ten months, babies are getting to know the words but have not been able to speak it and then say first words when he was about one year. Speech development of children, in general, will continue to grow rapidly so that in 
the age range of 16-24 months vocabulary possessed by children increased from 50 words to about 400 words. At the age of two years, children should be able to use verbs, adjectives, and disclosure themselves with a sentence consisting of two words. The age of three years, the way children talk already equaled the way adults talk informally. The child has mastered almost 1,000 words, can construct a sentence properly and can communicate well. Besides the language, children, in general, are also able to communicate with gestures and other symbols (Riyanti, 2002).

\section{Communication Development of Autistic Children}

One of the difficulties owned by an autistic child is in communication (Delphie, 2006). Therefore, the development of communication in children with autism is very different, especially in children who experience severe obstacles in the mastery of language and speech.

This is because the communication difficulties in children with autism are impaired in language (verbal and nonverbal), whereas language is the main medium of communication. They often find it difficult to communicate his wishes verbally (verbal / speech) and non-verbal (cues/gestures and writing).

Most of them can speak, using short sentences with simple vocabulary but his vocabulary is limited and difficult to understand. Due to the limited vocabulary of many words that they say do not understand. Those who can speak and imitate liked to imitate speech (echolalia). Some of them will often show the confusion of pronouns. For example, they do not use "I" and "You" correctly or do not understand when they are talking to switch from "You" into "Me" or vice versa (Peeters, 2009). By the time children are generally already know the name, they can respond to 'yes' and 'no,' understand the abstract concept of male-female and follow simple commands.

Meanwhile in autistic children may only echolalia to what is said or not speak at all. Children in general usually start talking about the age of six months. He/she began to speak in words at the age of one year and stringing two or three words in one sentence before eighteen months. While in autistic children, they did not have a pattern of language development. Their communication skills are diverse; some of them do not ever talk like children in general up to eighteen months or twenty months, sometimes it just disappears. Children with autism are difficult to talk. They often express themselves through behavior or desires. Indeed, for some cases of autistic children who have already able to convey his wishes by pulling the hand that near or points to the desired direction, or perhaps scream. If the parents or people around them do not understand what s/he wants, the child becomes angry, rage and perhaps the symptoms will appear.

Siegel (1996) describes the development of communication from autistic children divided into two parts, they are:

1. The development of verbal communication, including language delays even 
some of those who lost language skills, echolalia and use strange language or difficult to be understood, using simple language (e.g., for food: "Eat, yes!").

2. The development of non-verbal communication, including the use of gestures, body movements, expressed a desire for emotional expressions (screaming, angry, crying).

With the development of communication as mentioned above, it is clear that autistic child will encounter various difficulties to express his/her desire and with such communication skills, it needs a strategy which can help them to communicate with their environment.

\section{Speech Therapy}

Speech therapy is the provision of services to help someone in improving communication. It covers how to make voice and language, including the definition and wording used. With the development of science and technology, speech therapy can be done in several ways, both traditional and modern. In modern, speech therapy can be performed using software that is easily accessible by the client and can be done anywhere or anytime as the client desires. This method was discovered by Barbara based on her experience taking care for his father's speech impairment due to stroke. This therapy can increase the client's vocabulary because there are more than 700 questions in each stage of the lesson. Also, by using this program has the advantages such as; it can encourage increasing self-esteem, there is no limitation of time and place for independent study on this therapy, and storage of workout program automatically making it easier for clients to practice independently (Mystrokejourney, 2006). The main aim of speech therapy is to restore and improve the ability to communicate. In this regard include conversation, reading or writing, and also corrects a number / of a better word. The specific objectives include;

1. Clarity in speech.

2. Ability to understand simple words.

3. The ability to create attention.

4. The ability to get the word solid/clear and can be understood.

In carrying out this therapy requires patience and diligence because children often experience boredom and loss of enthusiasm for the practice.

Pictures Exchange Communication System is an approach to practice communication using verbal symbols (Bondy et al., 1994). PECS designed by Andrew Bondy and Lori Frost in 1985 and began to be published in 1994 in the United States. It was originally used for pre-school students who have autism and other disorders associated with communication disorders. Students who use their pecs are not encouraging language development, and they do not have the will to 
communicate with others. With the help of pictures or symbols of the understanding of the language that conveyed verbally can be clearly understood. Indeed, at the initial stage children are introduced to the symbols of non-verbal. However, in the final phase in the use of this PECS, children are motivated to speak. Although it is not a program to teach children with autism how to speak, in turn, it will encourage them to speak. Based on the experience of Wallin (2007), there are some advantages possessed by this approach, including:

1. Each exchange showed a clear objective and easy to understand. At the time of the child's hand pointing image or a sentence, it can be quickly and easily request or opinion it understood. Through Pecs, children have been given a smooth and easy way to find your needs.

2. From the beginning, the purpose of the communication is determined by the child. Children are not geared to respond to certain words or teachings are determined by adults, but the children are encouraged to independently obtain a "bridge" of communication and occur naturally. Teachers or coaches look for what the child wants to be a bridge reinforcement and communication with children.

3. Communication into something meaningful and high motivation for children with autism.

4. Materials (materials) used reasonably inexpensive, easy to prepare, and can be used anytime and anywhere. Symbols drawn PECS can be made by yourself or with photographs.

5. PECS does not limit a child to communicate with anyone. Everyone can easily understand the symbols Pecs so that children with autism can communicate with others not only with his own family.

Learning communication through this approach has to start from the object that kids want. Therefore, according to Bondy et al. (1994) in Gardner et al. (1999), the application of PECS needs for the use of behavior modification. Through behavior modification, it will be known what the kids want. The desired object will be reinforcement for the child to communicate through image exchange.

\section{Method}

This research was action research done collaboratively in order to know whether Speech therapy can improve English vocabularies of the autistic students of SMP LB Sunan Muria, Kudus. Burns (2010: 2) defines action research as part of a board movement that has been going on in education generally for some time. It is related to the ideas of reflective practice and the teacher as researcher. Furthermore, action research is research conducted in order to improve the teaching quality in teaching and learning process (Arikunto, et al., 2007: 57). So, it means that action research is 
the way to improve the system by using reflective practice which is done by the teacher as researcher (in the classroom). In other words, action research is conducted to reflect their way in teaching so that they can improve their teaching system. It will be done collaboratively with the English teacher of the school who will implement the action and the researcher as the observer of the students' progress. The cycle consists of eight meetings which will last for about two months.

This study used four instruments, e.g., observation, field notes, test, and interview. Observation is used to know how far the effect of the action has fulfilled the target. It is also used to know the activities of the teacher and the students during the process of Speech Therapy implementation. Meanwhile, field notes used to note the progress of the teacher and the students who are not available in the observation sheet. In this activity, the writer notes the unexpected phenomenon; which is not included in the observation sheet, but it happens in the class. Then, test is used to know the students' English vocabularies mastery. Moreover, the interview is used to know the strengths and weaknesses of using Speech Therapy in teaching English to autistic students.

\section{Promoting English Vocabulary for Autistic Students by Using Speech Therapy}

This research focused on the vocabulary mastery of the autistic students. From a total number of treatments in 12 meetings, it could be highlighted that the process of teaching consists of several stages. The following are steps commonly used by the teacher:

- Went out into yard of the school and observed how the social interactions take place and then had the student teacher interaction. In this activity, they were lead to identify the objects surrounding and also people met in the yard.

- They have worked on responding to unpredictable people or objects in the yard and their interactions. The teacher asked about their feeling, the description of the objects or people they met to construct meaning negotiation.

- Reviewing students' experience in the previous meeting by displaying some pictures they met in the yard and tried to have interactions with them from some simple questions given to them.

- The pictures were displayed more in the classroom by sticking them on the wall and whiteboard then they came and were free to take the picture which probably became a special memory for them or had particular characteristic than other pictures.

From those activities, students were quite excited about doing the activities. However, their speech production was still less. They still need intensive guidance from the teacher by raising more questions to stimulate their answers. When the chosen picture was on them, the speech which came out from them was their 
impression of it. So, most of the productions were in Javanese as their local language, such as "O-no" for a picture of Pak Yono as the gardener, "Yoss" for a picture of the new motor cycle they found in the yard. "Joss" was the word they wanted to express while showed their thumb to the teacher and some other expressions. Therefore, teacher should lead them to the target language of the pictures in English, such as "gardener," "motorcycle" or "bike", etc.

Based on observations made by the authors in the first cycle, teachers used primates in the application of speech therapy to teach autistic students at SMPLB Sunan Muria, Kudus. The teacher told the story of "the long nose" so that the students were interested in learning and listening carefully. During the story, the teacher also repeated a few words so that the students tried to imitate them to improve their pronunciation, after which the teacher gave some clues to the students asking some questions about the body parts that were both accidental and material. In addition to telling stories, students were also invited to sing and play related to the topic.

Motivation was given approximately five minutes always to encourage students to learn and try to focus. The primate way always involved students by communicating directly with students because students easily lose their concentration, so this interaction was very important to use. Also, icebreaking was done to keep students active during the learning process. This was the right way to start a lesson at SMPLB Sunan Muria, Kudus because students felt relaxed, enjoy their activities, ready to start lessons, interact well. The proximity of students and teachers was able to form so that the character of students with unstable emotions and irritability can be muted.

The next way used during the implementation of speech therapy was Academic Modification. Teaching and learning process was done by modifying materials and adjustment of the assessment and selection of materials to be simpler for students. The curriculum for autistic students of SMPLB Sunan Muria, Kudus, was designed based on the characteristics of students because it had limitations, namely intellectual function, memory, communication skills, and low motivation and learning disabilities. Students were only introduced simple English words that have not been arranged in the sentence. While the material for students with a seventh grade of autism was the same as the material for the fourth grade of elementary school thematic themes such as colors, transportation, animals, goods in class, goods at home. The process of teaching and learning also relied heavily on media aid as a visualization of learning so that students more easily grasp the teacher's intent. The media in the form of pictures, cartoons, dolls and real objects that students encounter in everyday life. Sometimes teachers used puppets to make students more interested in telling stories about the material.

Also, teachers also used real things in the teaching and learning process for autistic students, because their understanding process was very slow. Real media that 
exist around the students, for example, the goods in the classroom was very helpful for them to receive and understand the material well even though it was still at the level of vocabulary. Giving material could not always be in a classical way together. Individual reinforcement and drilling were more often done than the classical way. One English word for example "table" (/ terbl /) was taught with different intensity to the students. There were students who are four to five times able to understand and speak near the correct pronunciation in English. However, there were also students who need more drilling to be able to understand the meaning and say well.

Strengthening was also given in another form to the students. Rewards or awards to the students were given to make students more motivated and more focused in receiving the material because students were often easy to disrupt the focus with classroom situations both disturbance from other students and objects that exist in the class. The reward was a star and candy given to students who on that day have a good understanding and be good in a controlled sense than others. The reward was not given every meeting. The teacher explained the reason why they were rewarded, confirm and motivate the students to make the next meeting better. Strengthening was given more intensively in the classroom so that students are emotionally controlled and more motivated.

Evaluations given by teachers in the form of oral tests are inserted in the teaching process, and the results were qualitative. The assessment was done in every meeting not like normal class with specific time and more detailed assessment criteria. For example, the vocabulary material of the "bus, car, truck, plane, ship" vocabulary was given and assessed at each meeting with a target of five words fluently and knows what it means. The result showed the first meeting up to the third meeting of students was still difficult to say and try to understand the meaning of the word through the media used. The new progress could be seen in the fourth and fifth meetings when the students can say "wazz, has, walk, wen, hep" and know what it meant by pointing the appropriate image as it says (bus). At the sixth meeting, the drilling process was further improved. Submission of material made more varies, i.e., by modifying the explanation of the intended word (target) by modifying a simple word or phrase to bring to the target word so that the student more easily understands it.

\section{Conclusion}

The result of the study showed that the technique of Speech Therapy is an effective way to expose and improve autistic students' vocabulary. Some procedures used in Speech Therapy like direct interaction, academic modification, media drilling, and reward exposure brought students to better mastery of English vocabularies even it needs more extended periods. 


\section{References}

American Psychiatric Association [APA] (2000). Diagnostic and statistical manual of mental disorders, text revision DSM IV-TR. 4th ed. Washington, DC: American Psychiatric Association.

Arikunto, Suharsimi. (2006). Prosedur Penelitian Suatu Pendekatan Praktik. Jakarta: Rineksa Cipta.

Bondy, A.,\&Frost, L.(1994).ThePicture Exchange Communication System. Focus on Autistic Behavior, 9(3), 1-19.

Burn, Anne. (2010). Doing Action Research in English Language Teaching A Guide for Practitioners. New York: Routledge.

Carr EG, Kologinsky E. Acquisition of sign language by autistic children. II: Spontaneity and generalization effects. J Appl Behav Anal. (1983) Fall;16(3):297-314.

Cigna. (2005). Speech Therapy. Diambil pada 12 Pebruari 2006 dari http://www.cigna.com

Delphie, B. (2006). Pembelajaran Anak Autis. Klaten: Intan Sejati

Lord, C., \& Paul, R. (1997). Language and communication in autism. In D.J. Cohen \& F.R. Volkmar (Eds.), Handbook of autism and pervasive developmental disorders, 2nd edition (pp. 195-225). New York: John Wiley \& Sons.

Lovaas OI. Behavioral treatment and normal educational and intellectual functioning in young autistic children. J Consult Clin Psychol. 1987 Feb;55(1):3-9.

Miller. (2010). Activities to Promote Language with Autistic Learners. http://autism.lovetoknow.com/Activities_to_Promote_Language_with_Autistic _Preschoolers

Peeters, Theo. (2009). Panduan Autisme Terlengkap. Jakarta; Dian Rakyat

Siegel, B. (1996). The world of the autistic child: Understanding and treating autistic spectrum 
193 | VISION: JOURNAL FOR LANGUAGE AND FOREIGN LANGUAGE LEARNING

Wallin, David, J. (2007). Attachment in Psychotherapy. New York: Guilford Press.

Wire, V. (2005).Autistic Spectrum Disorders and Learning Foreign Languages. Support for Learning, 20(3).

Zager, Dianne, (2005), Autism Spectrum Disorders, Identification, Education and Treatment, New Jersey: Lawrence Erlbaum Associates, Publisher. 